\title{
Six year follow up of a consecutive series of patients presenting to the coronary care unit with acute chest pain: prognostic importance of the electrocardiogram
}

\author{
Malcolm J Metcalfe, John M Rawles, Carole Shirreffs, Kevin Jennings
}

\begin{abstract}
In a retrospective 6 year follow up data were obtained for 536 of $566(95 \%)$ consecutive patients admitted to a coronary care unit with acute chest pain. Their diagnoses were acute myocardial infarction in 290 (54\%), myocardial ischaemia in $164(31 \%)$, pericarditis in $16(3 \%)$, and non-cardiac in $66(12 \%)$. Six year mortality was $36 \%, 24 \%, 0 \%$, and $16 \%$ respectively. In patients with acute myocardial infarction a higher mortality rate during follow up was associated with a higher than average age, a higher than average creatine kinase, previous myocardial infarction, $Q$ wave infarction, and the presence of reciprocal changes. The presence of reciprocal changes was associated with higher than average concentration of serum creatine kinase, indicating more extensive infarction. Infarction complicated by ventricular fibrillation or left bundle branch block was associated with a higher death rate.

The electrocardiogram recorded at the time of acute myocardial infarction contains much useful prognostic information.
\end{abstract}

Several studies have reported mortality and prognostic patterns after myocardial infarction. ${ }^{1-3}$ Fewer studies have examined mortality in patients with either a diagnosis of cardiac ischaemia without infarction"-6 or "non-cardiac" chest pain. ${ }^{7}$ Furthermore, although many studies have identified subgroups of patients at risk, ${ }^{8}$ they have usually relied upon either predischarge or outpatient investigations. ${ }^{910}$ Unfortunately, many deaths may occur before these investigations can be performed (and acted upon) so there is a need for a method of identifying high risk patients from the time of admission. The electrocardiogram recorded during the hospital stay is often neglected or passed over for more complex investigations, but we have found it to be a useful prognostic indicator despite previous reservations about its importance..$^{10-12}$

To investigate these points we studied a consecutive series of patients presenting to a coronary care unit with acute chest pain who were followed up over a six year period.

\section{Patients and methods}

Over a one year period 566 consecutive patients presented to a coronary care unit with acute onset of chest pain. Follow up data were obtained for $536(95 \%)$, who are the subjects of this report. Their mean age was 55 years (range 24-78 years); 399 were male and 137 were female. Details of the electrocardiogram on presentation and of any subsequent changes or arrhythmias during the hospital stay were recorded, together with personal details and past medical history. The patients were followed up retrospectively by reference to their hospital case notes or by contact with their general practitioners. Details of subsequent cardiovascular events and the cause of death were obtained wherever possible.

The diagnosis of acute myocardial infarction was made if two of the following were present: a characteristic history of more than $\mathbf{3 0}$ minutes chest pain, a rise in the concentration of serum creatine kinase of $>75 \mathrm{U} / 1$, and the development of characteristic echocardiographic changes. All the electrocardiograms were recorded in 12 lead format at a paper speed of $25 \mathrm{~mm} / \mathrm{s}$ and $10 \mathrm{~mm} / \mathrm{mV}$.

We used the following definitions:

$Q$ wave myocardial infarction. The development of abnormal $Q$ waves in at least two adjacent infarct related leads.

Non- $Q$ wave myocardial infarct. Important $S T$ segment change or $T$ wave inversion in at least two adjacent inferior leads or three adjacent anterior leads not progressing to the formation of abnormal $Q$ waves, with these changes persisting for at least 24 hours.

"Enzymatic infarction". Acute chest pain with an abnormal rise of creatine kinase to at least twice the upper limit of normal but no significant electrocardiographic changes.

Reciprocal changes. ST segment depression $>1 \mathrm{~mm}$ at or after $0.08 \mathrm{~s}$ from the J point of the QRS complex in leads VI-V3 in inferior infarcts and leads 2, 3, and aVF in anterior infarcts. Posterior infarcts all showed reciprocal changes (qv). Only those patients showing reciprocal changes within 24 hours of admission were included in this category.

Ischaemic heart disease presenting as ST segment depression of $\geqslant 1 \mathrm{~mm}$ and/or $\mathrm{T}$ wave flattening or inversion with no permanent $S T$ or $T$ wave changes and no abnormal rise in 
Follow up data (mean 76 months (range 34-90)) on 536 patients with acute chest pain with various causes

\begin{tabular}{|c|c|c|c|c|}
\hline \multirow[b]{2}{*}{ Diagnosis } & \multirow[b]{2}{*}{ Number } & \multirow[b]{2}{*}{ Mean age } & \multicolumn{2}{|c|}{ Mortality $(\%)$} \\
\hline & & & 1 Month & 6 Years \\
\hline $\begin{array}{l}\text { Myocardial infarction } \\
\text { Myocardial ischaemia } \\
\text { Non-cardiac } \\
\text { Pericarditis }\end{array}$ & $\begin{array}{r}290 \\
164 \\
66 \\
16\end{array}$ & $\begin{array}{l}54 \\
53 \\
52 \\
47\end{array}$ & $\begin{array}{l}14(10-18) \\
1(0-3) \\
0 \\
0\end{array}$ & $\begin{array}{l}36(29-42) \\
24(17-31) \\
16(6-25) \\
0\end{array}$ \\
\hline
\end{tabular}

95"., Confidence intervals are shown in parentheses.

serum creatine kinase despite a characteristic history of chest pain.

Pericarditis. Characteristic history and clinical signs plus concave ST segment elevation but no permanent electrocardiographic change or rise in creatine kinase.

"Non-cardiac" chest pain. A history of chest pain with no supporting electrocardiographic changes (including a predischarge exercise test) or abnormal rise of serum creatine kinase on that admission.

The arrhythmias recorded, whether transient or permanent, were atrial fibrillation, supraventricular tachycardia, complete atrioventricular block, left bundle branch block, frequent ventricular extrasystoles, ventricular tachycardia, or ventricular fibrillation.

The peak concentration of serum creatine kinase was recorded, the upper limit of normal being $75 \mathrm{U} / 1$. An arbitrary distinction was made between mean peak enzyme concentrations above and below $1200 \mathrm{U} / \mathrm{l}$, indicating larger or smaller infarcts respectively.

All patients with a diagnosis of myocardial infarction underwent a limited exercise test before discharge. Any patients who did not complete this satisfactorily were started on a $\beta$ blocker and examined by cardiac catheterisation. They progressed to either bypass surgery or continued on medical treatment as appropriate. Patients with a diagnosis of ischaemic heart disease also underwent a full exercise test before discharge. If appropriate they had cardiac catheterisation.

Results were analysed by standard life tables calculated on a monthly basis. We compared groups by means of the log rank test. ${ }^{13}$

\section{Results}

Follow up data for a mean of 76 months (range 34-90 months) were obtained for 536 out of 566 $(95 \%)$ patients with the diagnoses of acute myocardial infarction, ischaemic heart disease, pericarditis, and "non-cardiac" chest pain. The table shows the 6 year mortality and figure 1 the life tables. In 11 out of 66 patients' with a "non-cardiac" diagnosis for the index event manifestations of ischaemic heart disease developed during follow up.

Survival after myocardial infarction was significantly worse than after the diagnoses of ischaemic heart disease $\left(\chi^{2}=8.7 ; p<0.01\right)$ but survival after a "non-cardiac" diagnosis was not significantly different from that after a diagnosis of ischaemic heart disease $\left(\chi^{2}=1.9\right.$; NS).

\section{MYOCARDIAL INFARCTION}

There were 194 patients with $Q$ wave myocardial infarction ( 31 had had a previous myocardial infarct), 52 with non- $Q$ wave infarcts, and 44 "non-specific" infarcts. Five of the 44 were "enzymatic infarcts", nine had left bundle branch block, and in 30 electrocardiographic data were incomplete. Thus complete electrocardiograpic data were available for 260 of the 290 patients with acute myocardial infarction.

In the first month mortality from myocardial infarction was $14 \%$ with a uniform annual mortality of $3.3 \%$ thereafter. There was no difference in mortality between the sexes and mortality during the first year was no different from that in subsequent years.

EFFECT OF AGE (fig 2)

Mortality was significantly higher for those patients aged above the median of 56 years at the time of myocardial infarction than in those aged 56 or below $(44 \%$ v $27 \%$ respectively $)\left(\chi^{2}=14.1 ; p<0.001\right)$.

\section{PREVIOUS INFARCTION}

Mortality was higher for those with previous infarction than in those without previous infarction $\left(\chi^{2}=4.5 ; \mathrm{p}<0.05\right)$.

\section{SEX}

There was no significant difference in mortality from myocardial infarction for men and women $\left(\chi^{2}=0.0 ; \mathrm{NS}\right)$.

CREATINE KINASE ABOVE AND BELOW $1200 \mathrm{U}$ L For the patients with full data on enzyme concentrations, the median serum creatine kinase concentration was $1200 \mathrm{U} / 1$. One hundred and twenty nine patients had a serum creatine kinase concentration of less than this median value; their 6 year mortality was less than that
Figure 1 Survival curves for acute myocardial infarction $(M I)$, ischaemic heart disease, and "non-cardiac" pain (95" ${ }^{\circ}$ confidence intervals are shown as shaded areas).

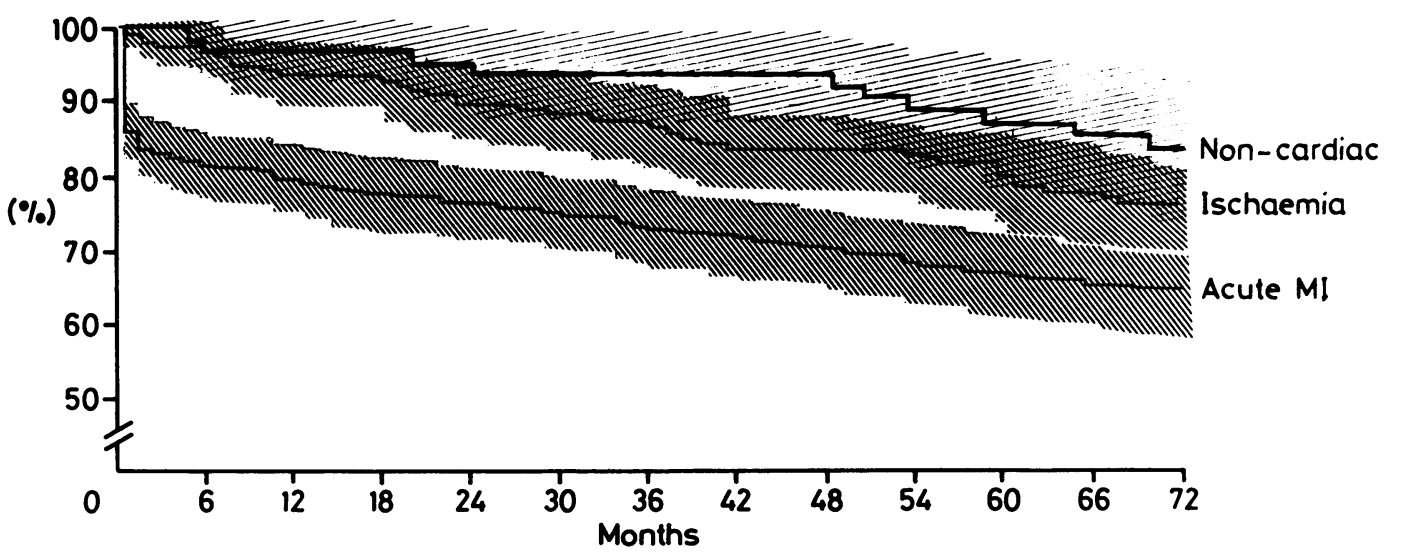


Figure 2 Survival curves for patients with myocardial infarction aged $<56$ years and $>56$ years $195 \%$ confidence intervals are shown as shaded areas).

Figure 3 Survival curves for patients with serum concentrations of creatine kinase $<1200 \mathrm{U} / \mathrm{l}$ and $>1199$ U/l $(95 \%$ confidence intervals are shown as shaded areas).

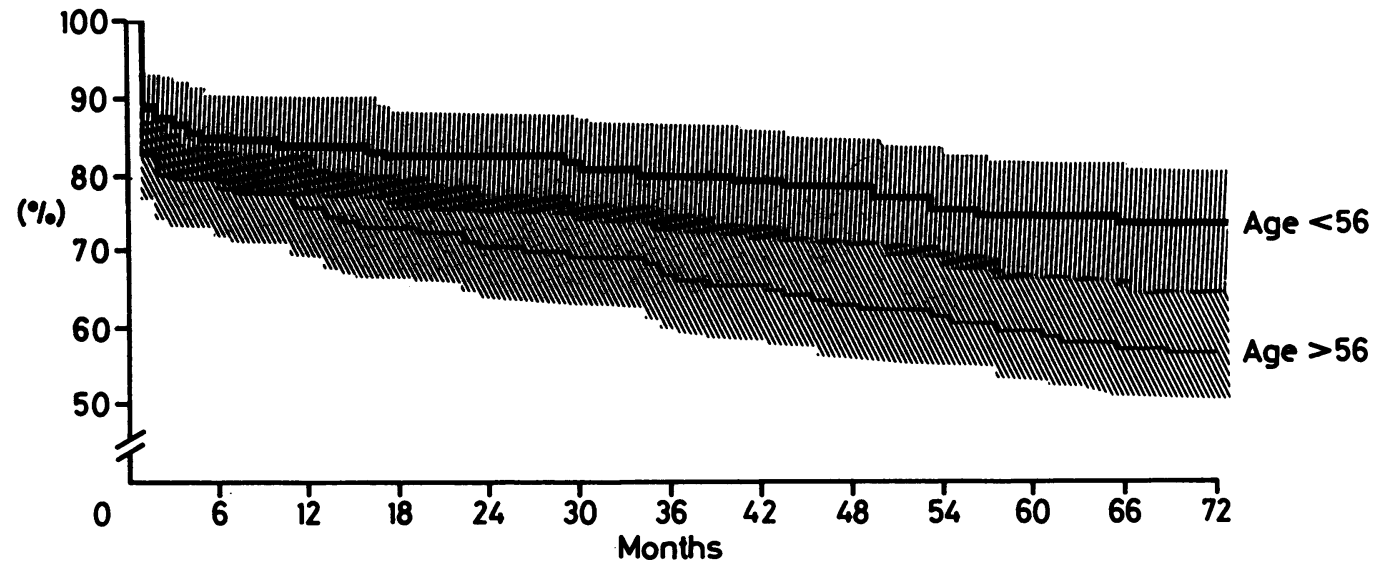

of the 135 patients with a value of $\geqslant 1200 \mathrm{U} / 1$ $\left(23 \% v 42 \%\right.$ respectively) $\left(\chi^{2}=10.9 ; \mathrm{p}<\right.$ 0.001 (fig 3 ). The mean age in both groups was 55.

SITE OF INFARCTION

The site of infarction was anterior in 147 $(50 \%)$, inferior in $103(36 \%)$, posterior in 16 $(6 \%)$, and uncertain in 24 cases $(8 \%)$. There was no significant difference in mortality between patients with anterior or inferior infarctions $\left(\chi^{2}=0 \cdot 5 ; \mathrm{NS}\right)$.

\section{RECIPROCAL CHANGES}

Two of the 260 patients with electrocardiographic evidence of myocardial infarction were excluded because the first electrocardiogram available for analysis was performed more than 24 hours after admission. The 105 patients with reciprocal changes had a higher mortality than the 153 patients without reciprocal changes $\left(\chi^{2}=10.9 ; \mathrm{p}<0.001\right)$ (fig 4). The mean age was 55 in each group but the mean concentration of serum creatine kinase was higher in those patients with reciprocal changes than those without (1999 $v 1279 \mathrm{U} / \mathrm{l} ; \mathrm{p}<0.001)$ Only eight of 105 patients with reciprocal changes had previously had a myocardial infarction compared with 25 of 153 patients without reciprocal changes $\left(\chi^{2}=4 \cdot 2\right.$; $\mathrm{p}<0.05)$.

\section{Q AND NON-Q WAVE INFARCTS}

Mortality was significantly lower in the 52 patients with non $Q$ wave infarcts than in those with $Q$ wave infarcts $\left(\chi^{2}=9.8 ; p<0.01\right)$ (fig 5). The patients with non- $Q$ wave infarcts also had lower mean concentrations of creatine kinase than those patients with $Q$ wave infarcts (1016 v $1689 \mathrm{U} / \mathrm{l}, \mathrm{p}<0.001)$

\section{MYOCARDIAL INFARCTION COMPLICATED BY} ARRHYTHMIAS

Ventricular fibrillation occurred in 35 patients, in whom the mean serum concentration of creatine kinase was $3246 \mathrm{U} / 1$. Mortality was higher than in patients with myocardial infarction without this complication $\left(\chi^{2}=20 \cdot 2\right.$; $\mathrm{p}<0.001$ ) (fig 6).

Myocardial infarction was complicated by ventricular tachycardia in 16 patients and by transient or permanent atrial fibrillation in 17 patients. In neither case was survival significantly different from that in patients without these complications $\left(\chi^{2}=3.3\right.$ and 0.5 respectively).

Ten patients had left bundle branch block (seven died during the first month of follow up)-a significantly worse survival rate than in those without this complication $\left(\chi^{2}=9 \cdot 6\right.$, $\mathrm{p}<0.01$ ).

\section{Discussion}

EFFECT OF INFARCT SIZE AND PREVIOUS MYOCARDIAL INFARCTION ON OUTCOME

The prognosis after myocardial infarction is strongly related to residual ventricular function. ${ }^{9}$ Patients with larger infarcts or prior myocardial infarction would, therefore, be expected to have a worse prognosis ${ }^{14-16}$ because

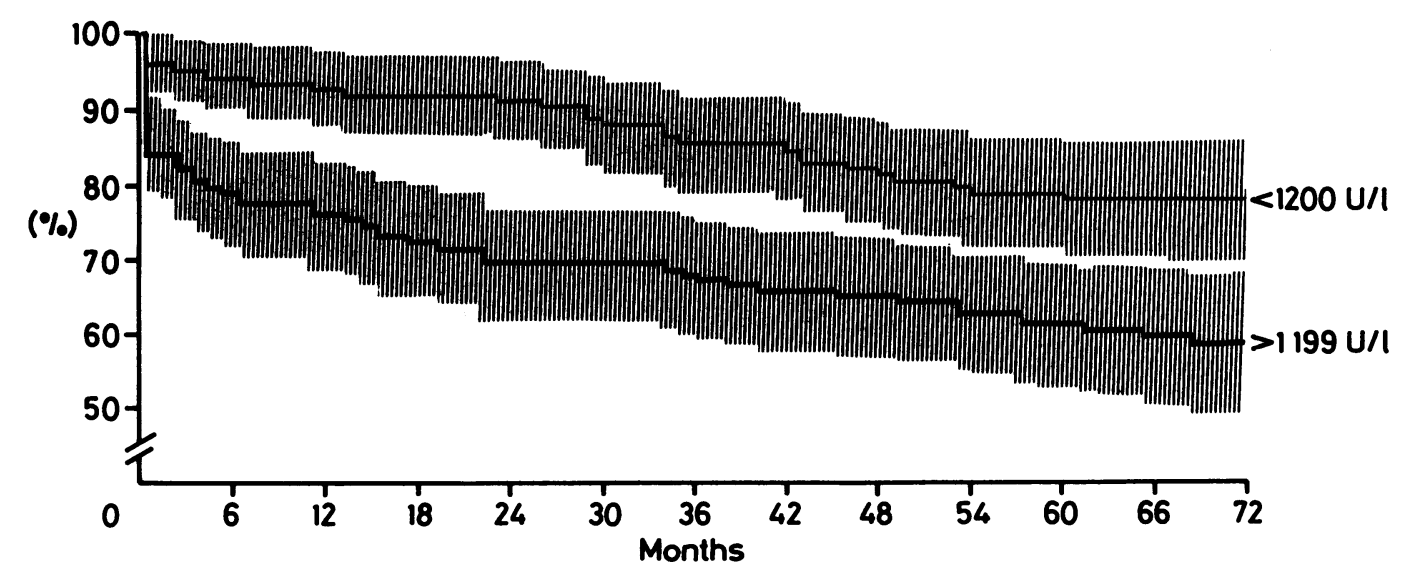


Figure 4 Survival curves for patients with and without reciprocal changes (95\% confidence intervals are shown as shaded areas).
$(\%)$

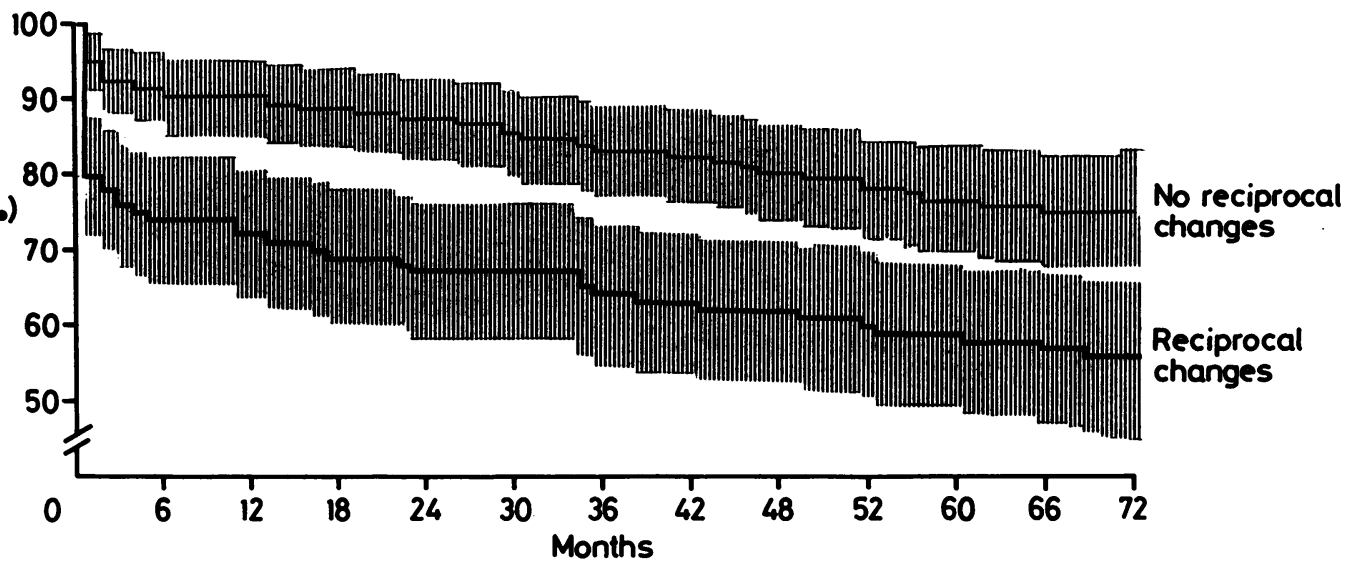

more extensive damage is associated with pump failure and ventricular fibrillation. ${ }^{91718}$ This is clearly shown in our study where the prognosis was worse for patients with prior myocardial infarction or with serum concentrations of creatine kinase above the median value.

\section{RECIPROCAL CHANGES}

The cause of the reciprocal changes seen on the electrocardiogram in acute myocardial infarction is still a matter of debate $e^{1920}$ but there is evidence of associated increased mortality. ${ }^{8}$ One view is that reciprocal change is purely an electrophysiological phenomenon, ${ }^{20}$ while an alternative view is that it indicates more extensive ischaemia or infarction. ${ }^{1819}$

If recriprocal change results from more extensive ischaemia or infarction, then patients showing this would be expected to have higher serum concentrations of cardiac enzymes and a worse prognosis; this is what we have shown. Interestingly, those patients showing reciprocal changes had significantly fewer previous infarctions, so for that reason this group would have been expected to have had a better prognosis. There was no significant age difference between the two populations to account for our findings. These data, therefore, strongly support the view that the presence of reciprocal changes acts as an early and independent marker for those patients at particularly high risk. This excess risk is manifested within the first month and continues thereafter.

SEX AND SITE OF INFARCTION

It has been suggested that women have a worse prognosis than men after myocardial infarction. $^{2122}$ Our data do not support this. The apparent difference in mortality between the sexes reported by others was most probably the result of the higher mean age of the women. ${ }^{23}$

In the past it was considered that anterior myocardial infarction carried a worse prognosis than inferior infarction, ${ }^{31421}$ although more recently this has been refuted. ${ }^{24} \mathrm{We}$ found no significant difference in mortality between the sites of infarction.

\section{$Q$ WAVE AND NON-Q WAVE INFARCTION}

There is still debate over the prognosis of patients with subendocardial infarction. It is widely believed that although there is a smaller initial mortality than for transmural infarctions, there is a substantial subsequent risk because many of these patients progress to transmural infarction..$^{25-27}$ If this were so then the survival curves for these two groups would tend to converge. ${ }^{27}$ Definitions of non-transmural infarction vary, ${ }^{28}$ and to complicate matters still further many transmural infarctions diagnosed at necropsy have not produced $Q$ waves on the surface electrocardiogram.

We did not see convergence of survival curves and a lower mortality was seen in the non- $Q$ wave group, presumably reflecting the smaller infarcts. ${ }^{28}$ In patients with non-transmural infarction, as we define it, there appears to be no reason for early investigation. This conclusion is supported by an extensive review of published reports ${ }^{29}$ and one large recent study ${ }^{28}$ which showed a better prognosis in patients with subendocardial infarction.
Figure 5 Survival curves for patients with $Q$ wave and non- $Q$ wave infarctions $195 \%$ confidence intervals are shown as shaded areas).

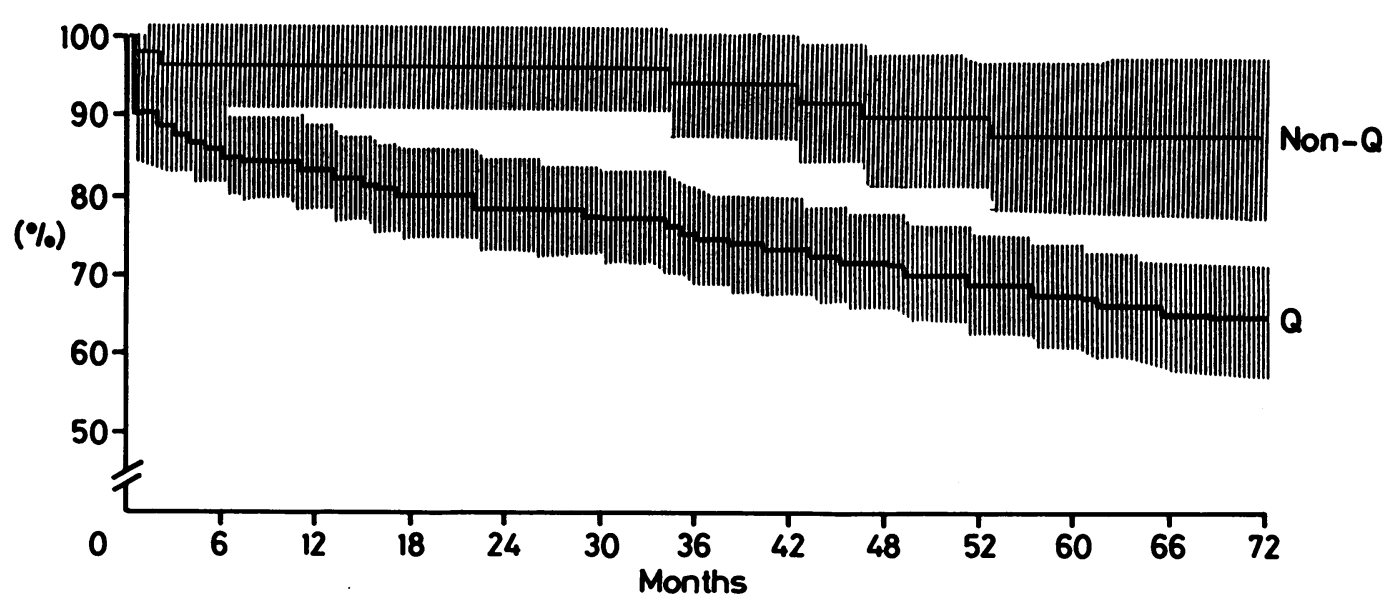


Figure 6 Survival curves for patients without ventricular fibrillation and with ventricular fibrillation $195 \%$ confidence intervals are shown as shaded areas).

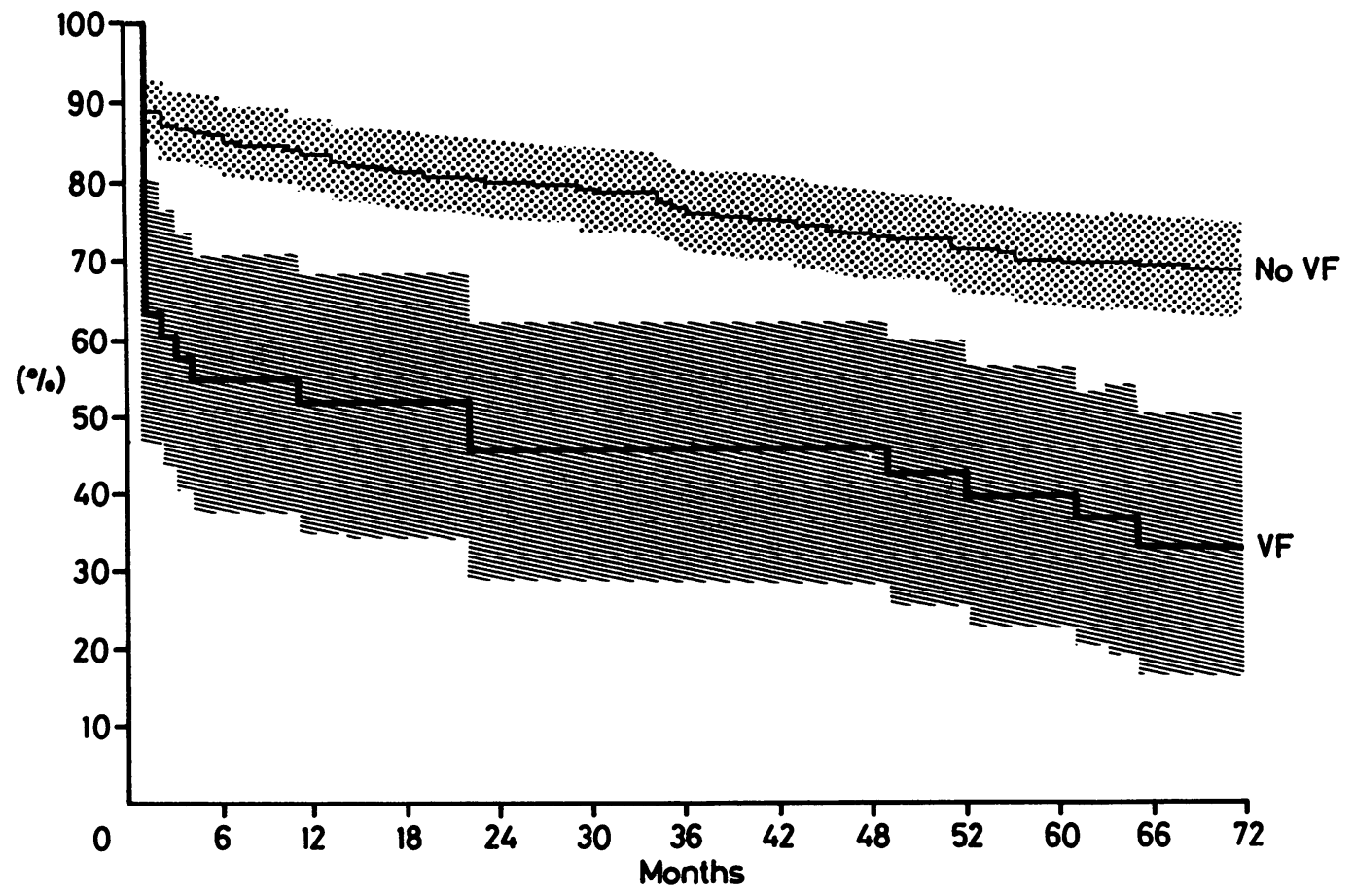

MYOCARDIAL INFARCTION COMPLICATED BY VENTRICULAR FIBRILLATION

If very early ventricular fibrillation is successfully treated it is not generally thought to carry such an adverse prognosis as later ventricular fibrillation. ${ }^{30}$ We did not distinguish between those patients with very early and those with later ventricular fibrillation but in view of the small numbers it is unlikely tht such analysis would have been conclusive. However, the larger an infarct the greater the likelihood of ventricular fibrillation developing. ${ }^{31}$ In this study the patients in whom ventricular fibrillation developed had a mean serum concentration of creatine kinase that was twice that for all infarcts, and mortality was significantly worse than for patients without ventricular fibrillation.

\section{CARDIAC ISCHAEMIA}

The prognosis of patients with chronic angina is usually thought to be quite good, and many hundreds of patients have been repeatedly exercised to induce angina, either during pharmaceutical studies or to improve exercise tolerance, without coming to harm. ${ }^{32} 33$

In our patients with a diagnosis of ischaemic heart disease outcome was not good. Although their initial mortality was low, their subsequent 6 year mortality was only one third less than that for patients with infarcts. Some might suggest that it is only the subset of patients who get admitted with unstable or severe angina that is at risk, but this is not supported by community studies. For example, Hobkirk followed up 307 out of 336 patients known to have chronic angina. Four years later $12 \%$ had died and $6 \%$ had undergone bypass grafting. Campbell et al followed up 1428 women with angina; by 12 years there was a $50 \%$ increase in their expected mortality. ${ }^{34}$

It has been postulated that patients with a history of chronic angina before infarction might have smaller infarcts and a better prognosis than patients without angina.$^{35}$ In theory, chronic angina should lead to the development of collateral vessels which protect the jeopardised myocardium. ${ }^{36}{ }^{37}$ Our own and previous studies, however, do not support this hypothesis. ${ }^{1321}$

\section{"NON-CARDIAC" CHEST PAIN}

Patients with a diagnosis of "non-cardiac" pain or "chest pain ? cause" are generally thought to have a good prognosis. Our study clearly showed that for our patients this was not so; the 6 year mortality $(16 \%)$ differed only marginally from that in patients diagnosed as having ischaemic heart disease. Smyllie reported similar results. ${ }^{7}$ In Smyllie's study at 6 years there was a $12 \%$ mortality for patients discharged with a diagnosis of angina and a $10 \%$ mortality for patients diagnosed as having "non-cardiac" pain. Wilcox et al noted a low one year mortality in patients with "non-cardiac" chest pain, ${ }^{38}$ which we have confirmed; but later manifestations of ischaemic heart disease suggest that in some cases the "noncardiac" diagnosis was mistaken. Our results suggest that patients with "non-cardiac pain" should perhaps be followed up more closely.

The electrocardiogram recorded at the time of acute myocardial infarction is of considerable prognostic value and could be used to identify patients who might benefit from early investigation and intervention. If the electrocardiogram shows reciprocal changes, or where infarction is complicated by ventricular fibrillation or left bundle branch block, patients are at particular risk. On the other hand, patients without reciprocal changes and those with non- $Q$ wave infarction are at relatively low risk. Patients in whom myocardial infarction is not confirmed, who are discharged with a diagnosis of ischaemic heart disease or "non-cardiac" pain, nevertheless, have an appreciable long term risk. 
1 Honey GE, Truelove SC. Prognostic factors in myocardial infarction. Lancet 1957; i:1155-61, 1209-12.

2 Schlant RC, Forman S, Stamler J, Canner PL. The natural history of CHD: prognostic factors after recovery from myocardial infarction in 2789 men. The 5 year findings of the coronary drug project. Circulation 1982;66:401-14.

3 Helmers C. Short and long term prognostic indicators in acute myocardial infarction. Acta Med Scand 1974;195: (suppl 555).

4 Engby $B$, Strunge $P$, Olsen $J$. The prognosis for patients referred with suspected acute myocardial infarction. Acta Med Scand 1985;217:465-71.

5 Hobkirk DW. Follow up study of angina in patients aged 3059 in general practice. $B r$ Med $J$ 1985;290:1477-9.

6 Schroeder JS, Lamb IH, Harrison DC. Patients admitted to the coronary care unit for chest pain: high risk subgroup for subsequent cardiovascular death. Am J Cardiol 1977;39:829-32.

7 Smyllie HC. Prognosis of patients discharged from a coronary care unit. Br Med J 1986;293:541-2.

8 Murray DP, Salih M, Tan LB, Murray RG, Littler WA Prognostic stratification of patients after myocardial infarction. Br Heart $J$ 1987;57:313-8.

9 Cleempoel H, Vainsel H, Bernard R, et al. Predictors of early death after acute myocardial infarction: two month follow up. Eur Heart $J$ 1986;7:305-11.

10 Iskandrian AS, Hakki A, Kottler MN, Segal BL, Herling I. Evaluation of patients with acute myocardial infarction: which test, for whom and why? Am Heart J 1985;109: 391-4.

11 Fioretti P, Tijssen JGP, Azar AJ, et al. Prognostic value of predischarge 12 lead electrocardiogram after myocardial infarction compared with other routine clinical variables. infarction compared with oth

12 Sitanen P, Pohjola-Sintonen S, Haapakoski J, Makijarvi M Pajari R. The mortality predictive power of discharge
ECG after first acute myocardial infarction. Am Heart $J$ ECG after first acut

13 Peto R, Pike MC, Armitage P, et al. Design and analysis of randomised clinical trials requiring prolonged observation of each patient II. Analysis and examples. Br J Cancer 1977;35:1-39.

14 Davis HT, DeCamilla J, Bayer LW, Moss AJ. Survivorship patterns in the posthospital phase of myocardial infarction. Circulation 1979;60:1252-8.

15 Luria MH, Knoke JD, Wachs JS, Luris MA. Survival after recovery from acute myocardial infarction: two and 5 year prognostic indices. Am J Med 1979;67:7-14.

16 Pardaens J, Lesaffre E, Willems JL, DeGeest M. Multivariate survival analysis for the assessment of prognostic factors and risk categories after recovering from acute factors and risk categories after recovering from acute myocardial infarction: the

17 Grande P, Nielsen A, Wagner GS, Christiansen C. Quantitative influence of serum creatine kinase isoenzyme MB estimated infarct size and other prognostic variables on one year mortality after acute myocardial infarction. $B$ Heart $J$ 1986;53:9-15.

18 Herlitz J, Hjalmarson A, Waldenstrom J. Five year mortality rate in relation to enzyme estimated infarct size in acute myocardial infarction. Am Heart J 1987;114:731-7.

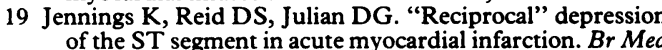

$J$ 1983;287:634-7

20 Mirvis DM. Physiologic basis for anterior ST segment depression in patients with acute inferior wall myocardial depression in patients with acute inferior

21 Cole DR, Singian EB, Katz LN. The long-term prognosis following MI, and some factors which affect it. Circulation 1954;9:321-34

22 Puletti M, Sunseri L, Curione M, Erba SM, Borgia C. Acute myocardial infarction: sex related differences in prognosis. Am Heart $J$ 1984;108:63-6.

23 Dittrich H, Gilpin E, Nicol P, Cali G, Henning H, Ross J. Acute myocardial infarction in women: influence of gender on mortality and prognostic variables. Am J Cardio 1988;62:1-7.

24 Robinson K, Conroy RM, Mulcahy R, Madden B. Relation of infarct site to 15 year prognosis in patients who survived for 28 days after a first myocardial infarction. Br Heart $J$ 1988;60:470-3.

25 Marmor A, Sobel BE, Roberts $R$. Factors presaging early recurrent infarct extension Am J Cardiol 1981;48: recurren

26 Rigo P, Murray M, Taylor DR, Weisfeldt HL, Strauss HW, Pitt $B$. Haemodynamic and prognostic findings in patients with transmural and non transmural infarctions. Circulation 1975;51:1064-70.

27 Herlitz J, Hjalmarson A, Bengtsson A, Sillfors L. Longterm prognosis in relation to ECG findings in acut myocardial infarction. Acta Cardiol (Brux) 1987;42: $79-89$.

28 Goldberg RJ, Gore JM, Alpert JS, Dalen JE. Non-Q wave myocardial infarction: recent changes in occurrence and prognosis-a community wide perspective. Am Heart $J$ 1987;113:273-9.

29 Nixon JV. Non Q wave myocardial infarction. Am J Med Sci 1986;292:173-81.

30 Lawrie DM, Higgins MR, Godman MJ, Oliver MF, Julian DG, Donald KW. Ventricular fibrillation complicating acute myocardial infarction. Lancet 1968;ii:523-8.

31 Dewhurst NG, Hannan WJ, Muir AL. Ventricular performance and prognosis after primary ventricular fibrillation Eur Heart $J$ 1984;5:275-81.

32 Bassan MM. Who's afraid of angina pectoris? Separating the symptom from the marker. Lancet 1986;ii:1442-3.

33 Redwood DR, Rosing DR, Epstein SE. Circulatory and symptomatic effects of physical training in patients with coronary artery disease and angina pectoris. $N$ Engl J Med 1972;286:959-65.

34 Campbell MJ, Elwood PC, Abbas S, Waters WE. Chest pain in women: a study of prevalence and mortality follow up in South Wales. J Epidemiol Community Health 1984;38: 17-20.

35 Warltier DC, Zyvoloski MG, Gross GJ, Brooks HL. Importance of retrograde coronary flow in the prediction of experimental myocardial infarct size. Cardiology of experimental

36 Fujista $M$, Sasayama S, Ohno A, Nakajima H, Asanoi H. Importance of angina for development of collateral circulation. Br Heart J 1987;57:139-43.

37 Schaper W, Nienaber C, Gottwik M. The importance of the collateral circulation for myocardial survival. Acta Med Scand 1981;suppl 651:29-35.

38 Wilcox RG, Roland JM, Hampton JR. Prognosis of patients with "chest pain ? cause". Br Med J 1981;282:431-3. 